Revista Oficial del Poder Judicial

ÓRGANO DE INVESTIGACIÓN DE LA CORTE SUPREMA DE JUSTICIA DE LA REPÚBLICA DEL PERÚ

Vol. 9, n. 11 , enero-junio, 2019, 441-444

ISSN versión impresa: 1997-6682

ISSN versión electrónica: 2663-9130

DOI: https://doi.org/10.35292/ropj.u9i11.13

\title{
$X$ Congreso Nacional de Jueces, Tacna 2017
}

\section{0 \\ DECLARACIÓN DE TACNA}

Los jueces del Perú reunidos en el X Congreso Nacional en la heroica ciudad de Tacna, los días 13, 14 y 15 de julio, luego de amplios debates llevados a cabo democráticamente, acordamos hacer públicos nuestros acuerdos, resumidos en lo siguiente:

1. EXPRESAMOS nuestro respaldo al presidente del Poder Judicial doctor Duberlí Rodríguez Tineo, en las políticas institucionales que viene implementando.

2. REAFIRMAMOS nuestro compromiso por brindar una justicia eficaz, eficiente y transparente, requiriendo, al mismo tiempo, se dé cumplimiento a la exigencia efectuada en el V Congreso de Jueces del año 2010, de contar con un presupuesto que permita al Poder Judicial cumplir con los objetivos y metas programadas para su adecuado desempeño institucional. Para ello demandamos reformar el artículo 145 de la Constitución Política del Estado, a fin de que se precise de manera inobjetable que el Poder Judicial goce de autonomía en la elaboración y aplicación de su presupuesto, 
el mismo que no puede ser inferior al $4 \%$ del presupuesto que se apruebe en el Poder Legislativo. Nos comprometemos a presentar, oportunamente, el proyecto correspondiente.

3. RECHAZAMOS los actos de violencia realizados por parte de las rondas campesinas en agravio de las señoras juezas: María Soledad Chuquillanqui Chinguel y Milagros Julisa La Torre Vázquez en los Distritos Judiciales de Piura y Sullana. Exigimos a los mismos el respeto a la autoridad judicial, debiendo ceñir su actuación a lo prescrito en la Ley de Rondas Campesinas n. ${ }^{\circ} 27908$.

Respaldamos el acuerdo del Consejo Ejecutivo del Poder Judicial, que ordenó al procurador del Poder Judicial proceda conforme a sus atribuciones, en tanto el Ministerio Público, dispuso los actos de investigación necesarios para el esclarecimiento de los hechos, los que deben ser conducidos bajo el principio de debida diligencia.

4. TRABAJAMOS por una administración de justicia moderna que, usando las nuevas tecnologías de la información, deje atrás el papel e implemente, progresivamente en el ámbito administrativo, un gobierno electrónico $\mathrm{y}$, en el ámbito jurisdiccional, el Expediente Judicial Electrónico (EJE). Por ello, expresamos nuestro convencimiento de que debemos dar pasos serios hacia la digitalización, al incremento del uso de las notificaciones y la firma electrónica, así como supervisar que las resoluciones se encuentren en el editor, con lo cual el mayor beneficiario será el destinatario del servicio de justicia: la ciudadanía.

5. RECONOCEMOS que la implementación de la oralidad del proceso penal y laboral representa una mejora significativa del servicio de justicia, y consideramos por tanto que debe extenderse de modo progresivo a todos los procesos judiciales, resguardando 
las exigencias tecnológicas y las particularidades que le son propias a cada especialidad.

6. VALORAMOS los esfuerzos creativos de todas las Cortes Superiores, que para mejorar el servicio a la ciudadanía vienen llevando a cabo buenas prácticas, las que deben ser identificadas, monitoreadas, sistematizadas e incluidas en el banco de buenas prácticas a cargo del Consejo Ejecutivo del Poder Judicial para su réplica a nivel nacional.

7. AFIRMAMOS que la aplicación del enfoque de género en el derecho es obligatoria y transversal para todos los jueces y juezas del país en todos los niveles y especialidades, pues los estereotipos de género sitúan en condición de desventaja a las mujeres y grupos vulnerables, para el reconocimiento y ejercicio de sus derechos de acceso a la justicia en igualdad de condiciones.

8. CONOCEDORES de que atravesamos una situación crítica y compleja debido a que la corrupción ha tejido su actuación en todas las esferas y niveles del Estado, ratificamos nuestro compromiso en la lucha contra la corrupción y la enfrentamos con integridad y valentía dentro de la función que nos toca cumplir conforme a la Constitución y la Ley, con imparcialidad y plena independencia.

9. EXPRESAMOS que la sanción a los jueces por ausencia de motivación en su resolución, es el único supuesto previsto en el inciso 13 del artículo 48 de la Ley de Carrera Judicial para el control disciplinario.

10. PRECISAMOS la necesidad de contar con un régimen pensionario único para los jueces del país, conforme a las funciones que ejercemos, por lo cual instamos a la Sala Plena del Poder 
Judicial para que de acuerdo a su iniciativa constitucional presente los proyectos de ley respectivos y pertinentes.

11. REAFIRMAMOS nuestro compromiso con la consolidación de nuestro sistema democrático de gobierno, para cuyo efecto propondremos la integración al Consejo Ejecutivo de un representante de los jueces de paz.

12. VALORAMOS la presencia del presidente constitucional de la República, Pedro Pablo Kuczynski Godard, en este congreso de jueces y juezas del Perú, como una expresión y reconocimiento de la separación de poderes y muestra de respeto a la autonomía e independencia judicial.

Tacna, 15 de julio de 2017 